\title{
The influence of digitalization on the emotional knowledge within the Romanian corporate context
}

\author{
Violeta Mihaela DINCĂ \\ Bucharest University of Economic Studies, Bucharest, Romania \\ violeta.dinca@fabiz.ase.ro
}

\begin{abstract}
The goal of this article is to examine the significance and the influence of the degree of emotional knowledge for the managers in relation with variables such as the employee performance, job satisfaction, and efficiency in a work environment impacted by digitalization. The study's research questions concentrated on analyzing the opinions of 35 respondents within a multinational beverage corporation concerning the relationships between their managers' level of emotional knowledge and their own work engagement, job satisfaction, and efficiency within the work environment. This phenomenological study disclosed that the capabilities of a manager in relation with emotional knowledge are very important for the managers' capability to lead people, engage them, increment job satisfaction, and increase their efficiency.
\end{abstract}

Keywords: emotional knowledge, digitalization, Romanian work environment.

\section{Introduction}

Since the 1990s' emotional knowledge is a concept which has been analyzed and taken into consideration in debates about corporate management. Emotional knowledge is emerging as a fresh and striking notion with impact for the decision making process and with resonance for the knowledge management area of studies. Emotional knowledge is shaped by emotions, and blended with cognitive knowledge into our mental representation of the world (Brătianu and Bejiranu, 2020). Emotions can be merely defined as being particular feedbacks to different experiences, operators and objects (Dooley and Gubbins, 2019; Dincă, 2020). Additionally, emotion is essential in the decision making process, taking the shape of knowhow that stimulates people to have appropriate responses to various outside stimuli (Garcia-Perez et al., 2020; Dincă, Lupulescu and Kitzelmann, 2020).

The paper includes a literature review regarding the emotional knowledge concept integrating the human interconnection of performance, job satisfaction, and engagement. Moreover the paper focuses on a main research question: "What are the perceptions among employees regarding their managers' degree of emotional knowledge in relation to their own motivation, job satisfaction, and performance?" by performing 35 zoom video interviews and afterwards identifying the layers and the relations between the managers' efficiency and the skills related to emotional knowledge.

\section{Literature review}

\section{The multifaceted framework of emotional knowledge}

Emotions have grown into significant attributes in social and professional contexts. Particularly in the years 2000 a big progress has been made in studies about emotions and the affective dimension, not just within scientific areas which traditionally research these concepts (like psychology, medicine or neurology), but also more sphere of humanities and social sciences (Serrano-Punche, 2015). Even though within Western cultures the analysis of the essence of human affection has 
constantly been displayed - ever since the literature of Aristotle, and more recently in Descartes, Spinoza or George Mead (Han, Yoon and Chae, 2020) - more recently emotions have arrived to be the research subject for various scientific areas (like as anthropology, economics, linguistics, etc.). In this sense, some of the most productive theories are those enhanced from the psychology (more specifically the social psychology) and the 'sociology of emotions' (Salinas-Avila et al., 2020).

Jaggar (1989) also recognized the importance of emotion in the process of inquiry. Our

emotions represent habituated responses to certain events that resonate with other similar experiences. They represent our emotional evaluations of different situations and so are essential to our processes of observation and understanding. We feel sad for others when they have suffered a loss; angry when we see others dominated or exploited. Such feelings can provoke us to action, to support or to challenge. This store of attitudes and evaluations forms our actions and can be seen as a store of knowledge. Emotions prompt us to act appropriately, to approach some people and situations and to avoid others, to caress and cuddle, fight or flee (Jaggar, 1989; Peile, 1998).

This progressive preoccupation for emotions within the academic environment is highly connected with the growth of the affective dimension for society as a whole, and obvious changes can be perceived for the delivery of affection on the private and public scenes. Simultaneously the society has also caught the social spread and expansion of Information and Communications Technology (ICT), as various technologies are completely fused in our daily activities or tasks, sometimes the delimitation between media and our everyday actions being very hard to do, because they have evolved into prerequisites of our life (Brosi and Schuth, 2020). However the integration and prevalence of digital devices cannot be tackled only from a quantitative point of view, but also thanks to their extensive diffusion, adjustment and the eventuality of constant connection that they build, we can underline their contribution of reconfiguring different facets of our existence (Hwang, Shi and Wang, 2021).

\section{Methodology}

In order to achieve the objectives set for the study a qualitative phenomenological study was performed. Within a multinational beverage corporation we analyzed the connection between the degree of the managers' emotional knowledge and the employees' engagement, performance and job fulfillment for a sample of 35 employees who are integrated in various teams. The data was gathered using in depth zoom, semi-structured interviews with 35 of the corporation's employees who are part of different digital teams and live in different countries such as Romania, Croatia, Greece, the Czech Republic and Hungary.

We inspected three sub research questions:

1. Assessing the managers' level of emotional knowledge, what influence does it have on the employee's work engagement?

2. Assessing the managers' level of emotional knowledge, what influence does it have on the employee's job satisfaction?

3. Assessing the managers' level of emotional knowledge, what influence does it have on the employee's work efficiency?

There were 35 male and female employees gathered for the study through the method of snowball sampling. Semi-structured interviews were applied as the main information collecting tool for this research with the goal to assess the relationship between managers' degree of emotional knowledge and the employees' level of engagement, performance and job fulfillment. The duration of each interview was of about 45 minutes. The questions integrated within the 
interview guide were open-ended on purpose in order to contribute to a thorough inquiry of the topic.

\section{Results and discussions}

The research included 14 men and 21 women respondents with ages between 25 to 58 years, of different nationalities and working in various teams of the research corporation. The respondents' nationalities consisted of 11 Romanians, 9 Croatian, 7 Greeks, 6 Czech and 2 Hungarians.

PICBE |

115

The method of thematic analysis was applied to review and assess the answers given by the respondents to the following three questions from the interview guide:

1. What is your opinion about the connection between your manager's emotional knowledge and your work engagement?

2. What is your opinion about the connection between your manager's emotional knowledge and your job satisfaction?

3. What is your opinion about the connection between your manager's emotional knowledge and your work efficiency?

All dialogues with the participants were organized through zoom in the period of OctoberNovember 2021. The thematic analysis was helpful in systematizing the information in an extensive way because it provided insights and explanation of lived experiences. Below a description of the results obtained is given for each question:

Question 1 - What is your opinion about the connection between your manager's emotional knowledge and your work engagement?

The aim of this question is to explore through the respondents' answers and find the meaning of their experience in relation to their own engagement and their managers' emotional knowledge skills. Around seventy-percent (70\%) of the participants at the study affirmed that their work engagement was influenced by their manager's emotional knowledge capabilities. There were also around $20 \%$ who asserted that their work engagement decreased because of the absence of their managers' absence of emotional knowledge skills. The other $10 \%$ claimed they were selfengaged so they were not impacted by their managers' lack of emotional knowledge skills.

Within the 35 respondents, 23 said they believe that during their time of being employed within the corporation their managers' emotional knowledge skills made their work engagement extend.

A Croatian respondent mentioned that his manager "owns a high level of emotional knowledge in the sense that he is very mindful, he detects rapidly when something annoys me and he many times shows he cares about anything that happens to me". A Hungarian respondent said that "he cultivated a work relationship with her manager based on harmony and respect and that the high level of emotional knowledge of her manager was a very important factor for that happening."

A similar statement was expressed by other 20 respondents who stated that when the managers show empathy or sympathy towards their employees' emotions, requirements and mindsets, through carefulness, support and warmth, they feel empowered and they feel their work engagement increases. For these respondents the managers were characterized with words such as "emotionally intelligent, encouraging, helpful, positive, well informed, considerate, warm and outgoing". Eleven respondents expressed that their managers' deficit of emotional knowledge skills had impacted negatively their work engagement and in these cases the managers were 
described with terms such as "belligerent, disagreeable, disinterested, arrogant, hesitant, individualistic and unreachable".

23 respondents asserted that their managers were preoccupied about how their employees are feeling about their day-to-day activities within the corporation and encouraged them to give a regular feedback and keep contact about the topic. In the same time, these managers met the professional and personal needs and took the necessary measures to make their employees recognize assistance, reassurance and welcome within the work environment. Nevertheless, 10 participants talked about conflicting or inopportune work episodes, mentioning their managers' lack of emotional knowledge skills. For example, these participants perceived their managers as disconnected from clients and fellow employees, and being focused only on the profit. Feedback and open communication were not welcomed and respondents specified that cooperating with their managers was not an agreeable experience and concluded that the lack of emotional knowledge from the part of their managers had a big influence on their own state of mind and on the quality of their work.

Question 2 - What is your opinion about the connection between your manager's emotional knowledge and your job satisfaction?

The goal of asking this question was to find out the respondents' insights from their professional experience in the context of their job contentment and their managers' emotional knowledge skills. Seventy-five percent (75\%) perceived their job satisfaction growing due to their manager's emotional knowledge skills while twenty-five percent $(25 \%)$ thought that because of their managers' shortage emotional knowledge skills, their job satisfaction had fallen. The rise in the job satisfaction given their managers' high level of emotional knowledge happened because of the sentiment of being supported, understood, valued and treated with esteem. Nineteen respondents mentioned that their bosses' style to praise them when they proved to be capable increased their job satisfaction in a significant way. Managers who developed an open communication with their workers were described as "observant, thoughtful, cordial and a team player" by these respondents.

In antithesis, twenty-five percent (25\%) of the participants believed that their job satisfaction decreased because of their managers' shortfall of emotional knowledge skills. They pointed out their managers were being unjustly biased, critical, disrespectful and indifferent with some respondents thinking that they had more insight and expertise than their managers on some topics or work activities. Around ten respondents declared that their managers did not have the capability to properly comprehend what their work actually consists in and, moreover, pushed for "unrealistic outcomes" without providing the proper support. Several respondents also claimed did not acquire training or coordination from their manager, but were continuously being held accountable for any error that appeared. The job satisfaction was low for employees who were managed by bosses who were not being productive communicators, who were declining to offer feedback, and failing to listen. Some participants disclosed that did not take any action towards their managers' attitudes because they were scared managers retaliating against them.

All the affirmations made by the respondents reinforced the statement that there is a correlation between the manager's emotional knowledge skills and the employees' level of job satisfaction. The participants who stated that their managers have deficit of appreciating and recognizing their work achievements also specified that these situations generated a decline in their job satisfaction. On the opposite side, the participants experiencing job satisfaction remarked that their managers acknowledged their achievements and manifested respect for their work and efforts. 
Question 3 - What is your opinion about the connection between your manager's emotional knowledge and your work efficiency?

The purpose of this question is to expose the respondents' opinions about the relationship between the managers' emotional knowledge skills and the employees' work efficiency.

Eighty percent $(80 \%)$ of the participants experienced an increase in work performance resulting from their manager's emotional knowledge skills while twenty percent $(20 \%)$ viewed their performance at the workplace lowering because of their manager's shortcomings of emotional knowledge skills. Participants, who perceived their productivity growing thanks to their manager's emotional knowledge skills, mentioned how their managers provided assistance, encouragement and constructive inspiration to boost a better performance from them.

One Greek respondent declared that his "manager stimulated feedback and always requested our opinion to identify new ways to resolve issues which created a sense of joy and made me and other colleagues feel positive".

Participants who alleged that their performance enhanced due to their managers' emotional knowledge skills were described as: supporting, considerate, good communicator, attentive, confident and optimistic. Twenty percent (20\%) of the respondents viewed their managers' gap of emotional knowledge skills lowered their efficiency and they used words like "unapproachable, stiff, tough, micromanaging, hostile, creating a stressful working environment and unreasonable".

One Czech respondent stated that his "manager provoked me to not perform at my best; I gave up caring how I perform anymore, because my manager's temper and feedback were almost always negative".

\section{Conclusion}

This study's outcomes disclosed many interesting aspects about the relationship between the managers' emotional knowledge capabilities and how the employees are being empowered by those abilities. The research exposed that the managers' capability to manage, engage, and coach employees also had the skill to generate a connection with the employees.

Managers who were considered sympathetic, kind, able to relate, understanding, and enthusiastic were also capable to reinforce the participants' the work engagement, job satisfaction and work efficiency.

We conclude that organizations should increase their competence in hiring managers with an increased level of emotional knowledge skills and should also get more efficient in developing them in this direction. In the academic environment, university management teams should implement emotional knowledge skills within their programs in order to prepare future managers to be stronger in their qualities as empathy, social abilities, interpersonal, and intrapersonal capabilities and adaptive leadership abilities.

\section{References}

Brătianu, C., and Bejinaru, R. (2020). Knowledge dynamics: a thermodynamics approach. Kybernetes, 49(1), 6-21, DOI: 10.1108/K-02-2019-0122.

Brosi, P., and Schuth, M. (2020). "Leaders' Emotion Expressions in Digital Communication: Social Distance in Leader - Follower Relationships", Härtel, C.E.J., Zerbe, W.J. and Ashkanasy, N.M. (Ed.) Emotions and Service in the Digital Age (Research on Emotion in Organizations, Vol. 16), Emerald Publishing Limited, Bingley, 95-103. 
Dincă, V. M. (2020). Factors with impact on the knowledge management practices within shared service centers. Proceedings of the International Conference on Business Excellence, 14(1).

Dincă, V.M., Lupulescu, G.M.G., and Kitzelmann, E. (2020). Organizational Knowledge Sharing Overview - Early 2020s Assessment, The $3^{\text {rd }}$ International Conference on Economics and Social Sciences Innovative models to revive the global economy October 15-16, Bucharest University of Economic Studies, Romania.

PICBE |

118

Dooley, L., and Gubbins, C. (2019). "Inter-organisational knowledge networks: synthesising dialectic tensions of university-industry knowledge discovery", Journal of Knowledge Management, 23(10), 2113-2134.

Garcia-Perez, A., Cegarra-Navarro, J.G., Bedford, D., Thomas, M., \& Wakabayashi, S. (2020). Critical capabilities and competencies for knowledge organizations. Bingley: Emerald Publishing.

Han, S.H., Yoon, S.W., and Chae, C. (2020). "Building social capital and learning relationships through knowledge sharing: a social network approach of management students' cases", Journal of Knowledge Management, 24(4), 921-939, https://doi.org/10.1108/JKM-112019-0641.

Hwang, Y., Shi, X.(C)., and Wang, X. (2021). "Hospitality employees' emotions in the workplace: a systematic review of recent literature", International Journal of Contemporary Hospitality Management, 33(10), 3752-3796.

Jaggar, A. M. (1989). Love and Knowledge: Emotion in Feminist Epistemology. In A.M. Jaggar, \& S.R. Bordo (Eds.), Gender/Body/Knowledge. Rutgers University Press: New Brunswick.

Peile, C. (1998). Emotional and Embodied Knowledge: Implications for Critical Practice. The Journal of Sociology \& Social Welfare, 25(4).

Salinas-Ávila, J., Abreu-Ledón, R., and Tamayo-Arias, J. (2020), "Intellectual capital and knowledge generation: an empirical study from Colombian public universities", Journal of Intellectual Capital, 21(6), 1053-1084.

Serrano-Punche, J. (2015). Emotions and Digital Technologies: Mapping the Field of Research in Media Studies, MEDIA@LSE Working Paper Series. 